\title{
Espaços, recursos escolares e habilidades de leitura de estudantes da rede pública municipal do Rio de Janeiro: estudo exploratório
}

\author{
Roberta Araújo Teixeira
}

Pontifícia Universidade Católica do Rio de Janeiro, Departamento de Educação

\section{Introdução}

Superadas as metas da universalização do ensino fundamental e da melhoria da regulação do fluxo de estudantes da educação básica no Brasil, a preocupação central desloca-se para a qualidade do ensino oferecido nas escolas do país.

Nos últimos anos, importantes indicadores na área da educação têm colaborado para a compreensão da realidade educacional brasileira. Tais indicadores são provenientes, em parte, de avaliações em larga escala, como o Sistema de Avaliação da Educação Básica (SAEB), a Prova Brasil, avaliações estaduais de redes de ensino e o Programa Internacional de Avaliação de Estudantes (PISA). Entre os resultados obtidos, destaca-se o desempenho insatisfatório dos estudantes brasileiros ao final da $4^{\mathrm{a}}$ série do ensino fundamental, ainda inferior ao patamar considerado adequado à consolidação e ao desenvolvimento das habilidades de leitura que permitirão aos alunos continuar a aprender com bom aproveitamento. No PISA, que avaliou, em 2000, a capacidade de leitura de alunos com 15 anos de idade em 32 países, o Brasil ficou posicionado no último lugar. Os resultados dessas avaliações em larga escala contribuíram com novas evidências para o debate sobre a qualidade de certas práticas pedagógicas de ensino da língua e sobre possíveis estratégias de enfrentamento das dificuldades dos alunos em aprender a ler e escrever.

Diante desse cenário, pesquisadores brasileiros intensificam a busca pelos fatores que constituem escolas de qualidade e que influenciam no ensino e na aquisição pelos educandos de habilidades cognitivas de leitura e matemática (Soares, 2005; Franco \& Bonamino, 2005; Bernado, Felipe \& Pedrosa, 2008).

Pesquisas realizadas por Soares (2005) e Franco e Bonamino (2005) indicam que, no Brasil e em outros países da América Latina, ao contrário dos países desenvolvidos, a infraestrutura física da escola e os recursos escolares aparecem como aspectos fundamentais para o desempenho escolar dos alunos, mesmo quando os resultados são controlados pelo nível socioeconômico dos estudantes. Dentre esses aspectos físicos da escola, destaca-se a infraestrutura do prédio, a presença, o estado de conservação e a utilização de espaços didático-pedagógicos tais como bibliotecas, 
salas de leitura, salas de aula e pequenas bibliotecas no interior das salas de aula (Franco et al., 2006; Bernado, Felipe \& Pedrosa, 2008). Nessa perspectiva, a ênfase não recai sobre a associação entre fatores materiais e resultados, mas sim sobre as características das próprias escolas, sua organização e processos que nelas se desenvolvem para alcançar os determinados resultados escolares (Franco \& Bonamino, 2005). No contexto brasileiro, o Projeto Estudo Longitudinal da Geração Escolar 2005 (GERES), ${ }^{1}$ fonte de dados desta pesquisa, tem colaborado de maneira significativa na linha de investigação das escolas eficazes. A pesquisa ora apresentada se constitui em desdobramento desse projeto, compondo uma das etapas dos estudos exploratórios realizados nos estabelecimentos de ensino participantes no polo do Rio de Janeiro, que tem como foco a análise dos espaços escolares relacionados ao desenvolvimento de habilidades de leitura.

Autores como Viñao Frago e Escolano (2001), Faria Filho et al. (2004), Viñao Frago (2005) e Vidal (2005) compreendem os espaços e objetos escolares como importantes constituintes de dimensões educativas relacionadas ao desenvolvimento de disposições cognitivas. Segundo Vidal (2005) e Viñao Frago e Escolano (2001), a observação dos espaços e objetos escolares pode revelar características de práticas escolares que acontecem no interior dos estabelecimentos de ensino, aumentando assim o entendimento do conjunto de saberes e de práticas ativados na escola. Dessa

${ }^{1}$ O Projeto GERES é um estudo longitudinal que acompanha a evolução da aprendizagem de leitura e matemática de um mesmo grupo de aproximadamente 21.000 estudantes de 303 escolas distribuídas em cinco cidades brasileiras no início do ensino fundamental entre 2005 a 2008. O principal objetivo do Projeto é investigar as práticas educativas e as condições escolares que contribuem para a promoção da eficácia escolar e da equidade intraescolar. $\mathrm{Na}$ vertente quantitativa, o GERES conta com instrumentos cognitivos (testes de habilidades de leitura e de matemática) e questionários contextuais aplicados a alunos, responsáveis, diretores, professores e coordenadores das instituições participantes. Na vertente qualitativa, no Rio de Janeiro, conta com estudos exploratórios realizados nos estabelecimentos de ensino participantes. forma, os aspectos materiais dos estabelecimentos de ensino compõem um fator relevante na constituição de determinadas práticas que podem constranger ou estimular a disseminação de certos conhecimentos e habilidades escolares.

Associando esta perspectiva teórica à necessidade de se realizarem novos estudos complementares com o intuito de verificar a especificidade de fatores de eficácia escolar no Brasil (Franco \& Bonamino, 2005; Soares, 2005), foi realizada, ao longo do ano de 2007, uma viagem de reconhecimento pelos espaços de três escolas públicas municipais, procurando perceber o que ensinam as paredes de suas salas de aula, pátios e corredores com seus murais em que são expostas as produções escritas dos alunos e a organização dos espaços das salas e cantinhos de leitura, de modo a identificar o que esses espaços e objetos propiciam, no sentido de tornar mais ou menos significativo o tempo que as crianças passam na escola. Assim, a pesquisa tem por objetivo a identificação de evidências de aspectos escolares relacionados a fatores promotores de aprendizagem de habilidades de leitura em espaços como salas de leitura, murais e cantinhos de leitura.

Para apresentar esta pesquisa, organizamos o artigo em quatro seções. Na primeira, são apresentados os principais referenciais teóricos que nortearam a construção da pesquisa. Na seção seguinte, são descritos os caminhos metodológicos da investigação, os critérios utilizados na escolha das escolas que constituíram o universo desta pesquisa e as etapas iniciais dos estudos exploratórios do GERES, bem como as categorias de análise. A terceira destina-se à apresentação e análise dos dados. Na última seção são apresentadas as conclusões do estudo e as contribuições desta pesquisa para o campo educacional.

\section{Principais pressupostos teóricos}

No âmbito da literatura nacional sobre escolas eficazes, Franco e Bonamino (2005) indicam que os fatores associados à eficácia escolar na literatura de pesquisa educacional brasileira podem ser descritos em cinco categorias: Recursos escolares; Organização 
e gestão da escola; Clima acadêmico; Formação e salário docente; e Ênfase pedagógica.

Diferentemente do que se observa nos países desenvolvidos, no Brasil as condições de infraestrutura das escolas constituem fatores relevantes para o resultado escolar dos alunos. A esse respeito, Barbosa e Fernandes (2001) concluem que as condições físicas, assim como o ambiente escolar, têm um impacto positivo sobre a proficiência dos estudantes em qualquer uma das cinco grandes regiões do Brasil. Soares (2007), em estudo sobre eficácia e equidade escolar, sugere que as condições de funcionamento de espaços destinados a atividades pedagógicas associadas a seu uso efetivo influenciam positivamente nos resultados escolares dos alunos. O autor destaca que o fato de os recursos escolares não representarem fatores de eficácia escolar em outros países, principalmente nos países desenvolvidos, justifica-se porque os equipamentos e o grau de conservação das escolas variam pouco de escola para escola, uma vez que praticamente todas as escolas possuem recursos básicos para seu funcionamento. No caso do Brasil, percebe-se que ainda há grande variabilidade no que tange aos recursos disponíveis nas escolas (Franco \& Bonamino, 2005).

De maneira complementar, Pedrosa (2007) destaca que o clima acadêmico das instituições de ensino pode ser representado pela ênfase no processo de ensino-aprendizagem em relação a outras demandas sociais tipicamente enfrentadas pelas escolas públicas. Dentre as práticas escolares apontadas pela autora, podemos citar a exigência, o interesse e a dedicação do professor, o oferecimento de um ambiente intelectualmente desafiador para os alunos e a utilização de recursos didático-pedagógicos com a finalidade de despertar o interesse na classe e expor novos temas, dimensões que reportam à importância dos aspectos materiais na escola.

Na revisão da literatura sobre os espaços escolares, verifica-se que os espaços e objetos presentes nas escolas são elementos constitutivos de atividades educativas relacionadas com o desenvolvimento de disposições cognitivas (Viñao Frago \& Escolano, 2001; Viñao Frago, 2005; Faria Filho et al., 2004;
Vidal, 2005). Dessa literatura desprendem-se duas ideias-chave que embasaram a pesquisa: a primeira ressalta que, por meio do estudo dos espaços e objetos escolares, é possível revelar aspectos das práticas pedagógicas que acontecem no interior dos estabelecimentos de ensino, aumentando assim o entendimento do conjunto de saberes e de práticas mobilizados pela escola. Nessa perspectiva, a materialidade da escola representa um fator relevante na constituição de determinadas práticas escolares, que constrangem ou estimulam a disseminação de certos conhecimentos e habilidades escolares. Assim, os espaços e objetos escolares, bem como sua existência, estado de conservação, disposição e utilização, são tomados neste estudo como mediadores culturais em relação à formação de disposições escolares e, portanto, como elementos significativos da dimensão ensino-aprendizagem. A segunda ideia-chave refere-se à dimensão tácita existente na organização dos espaços escolares. Com efeito, a decoração das dependências da escola, a composição e organização dos objetos nela dispostos constituem um "programa educador" tácito, que é oferecido pelos professores e pela escola e aprendido e internalizado pelas crianças como padrões culturais e pedagógicos (Viñao Frago \& Escolano, 2001; Viñao Frago, 2005; Vidal, 2005).

Partimos, então, da ideia de que compreender o que ocorre nas escolas e salas de aula é tarefa que envolve, entre outras, a discussão da organização do espaço escolar e das salas de aula para o trabalho com a leitura e a escrita. A perspectiva adotada apoia-se na compreensão de que na escola há concepções de ensino-aprendizagem da leitura e da escrita subjacentes à definição dos espaços para atividades individuais e grupais, à existência e uso de cantinhos e salas de leitura, ao lugar destinado aos livros e outros suportes da escrita, como os murais. Conferimos aos murais uma importante dimensão espacial no que se refere ao desenvolvimento de práticas de leitura. Situados em áreas externas das escolas, como pátios e quadras, bem como no interior das salas de aula, corredores, salas de professores e salas de leitura, entre outras dependências escolares, os murais apresentam-se 
como um espaço de suporte privilegiado da leitura e da escrita na escola. Considerado um poderoso canal de comunicação na escola, os murais escolares têm por finalidade veicular informações de naturezas distintas, além de comportar uma infinidade de possibilidades de gêneros textuais.

A propósito das diferentes práticas pedagógicas de ensino da leitura e da escrita correntes na escola brasileira nos dias de hoje, a literatura que deu suporte para a compreensão da dimensão teórica e operacional dos achados da pesquisa sobre habilidades dos alunos com textos ressalta as diferentes dimensões dos conceitos dos processos de letramento e alfabetização (Mortatti, 2006; Carvalho, 2005; Soares, 2003). Soares (2003) acredita que um dos fatores explicativos do fracasso do processo de ensino e aprendizagem da língua vivenciado nas escolas brasileiras atualmente é a série de equívocos em torno desses conceitos, que levou a concebê-los como fusão de dois processos e prevalecendo o conceito de letramento em detrimento do conceito de alfabetização. Soares (2003) e Carvalho (2005) mencionam que, mesmo havendo necessariamente relação entre alfabetização e letramento, é fundamental especificar suas diferenças sem, no entanto, dissociá-los. Por isso, Soares concebe a alfabetização e o letramento como processos interdependentes, indissociáveis e simultâneos.

Ao mesmo tempo, para uma abordagem de ensino balanceada, deve-se reconhecer a especificidade da alfabetização e a importância de que ela se desenvolva num contexto de letramento. Além disso, reconhece também que a alfabetização e o letramento têm facetas diferentes, cada uma com demandas metodológicas distintas, algumas caracterizadas por ensino direto, explícito e sistemático. Nesse contexto, Carvalho (2005) destaca a diferença existente entre a alfabetização e o letramento: "alfabetizar é ensinar o código alfabético, letrar é familiarizar o aprendiz com os diversos usos sociais da leitura e escrita" (p. 65). Nessa direção, a respeito do letramento, podem-se destacar práticas voltadas para a imersão das crianças na cultura escrita e em experiências variadas com a leitura e a escrita, o acesso ao conhecimento e a interação com diferentes tipos e gêneros de material escrito. No que se refere à alfabetização, destacam-se as práticas que desenvolvem a consciência fonológica e fonêmica dos alunos, a identificação das relações fonema-grafema, as habilidades de codificação e decodificação da língua escrita e o conhecimento e reconhecimento dos processos de tradução da forma sonora da fala para a em unidades gráficas (Carvalho, 2005).

É importante ressaltar que, com a pesquisa realizada, não tivemos a pretensão de defender, classificar ou apontar como melhor ou pior uma ou outra abordagem de alfabetização. Esta revisão de literatura embasou a análise dos achados da pesquisa em relação às ênfases dadas à leitura e à escrita no âmbito das três escolas investigadas.

\section{Percursos metodológicos}

A pesquisa, de natureza eminentemente qualitativa, resultou de um estudo exploratório realizado em três escolas públicas municipais participantes do Projeto GERES no Rio de Janeiro. Para a escolha delas, fez-se uso dos resultados da proficiência dos alunos em leitura nas duas primeiras avaliações do GERES, em março e novembro de 2005 . $^{2}$

As informações coletadas nas duas primeiras etapas exploratórias do GERES também foram utilizadas. Na primeira etapa, cada uma das sessenta e oito escolas participantes do GERES no município do Rio de Janeiro foi visitada entre os meses de maio e setembro de 2005 para documentação de aspectos materiais e pedagógicos relativos à infraestrutura escolar e das salas de aula, aos tipos de rituais e interações e aos recursos pedagógicos utilizados, a partir roteiros de observação e registros fotográficos. Na segunda etapa, em 2006, foram investigadas seis das trinta escolas municipais da cidade do Rio de Janeiro que apresentaram resul-

\footnotetext{
${ }^{2}$ É crucial ressaltar que, embora tenhamos consciência da
} importância das variáveis de nível socioeconômico (NSE) dos alunos em pesquisas dessa natureza, não as consideramos no processo de seleção das escolas porque não tivemos acesso a esses dados na ocasião do princípio de nossa pesquisa. 
tados diferenciados nas duas primeiras avaliações do GERES. Nessa etapa, foi realizada uma investigação mais adensada de diferentes aspectos espaciais e materiais das escolas e foram realizados novos registros fotográficos, entrevistas com professores e diretores e observações nas turmas participantes do GERES. Para dar continuidade aos estudos exploratórios, foi conduzida a terceira etapa, no ano de 2007. Nesta, foram visitadas três instituições do conjunto das seis escolas investigadas na etapa anterior. É da terceira etapa que este artigo trata.

O Gráfico 1 ilustra os desempenhos das escolas escolhidas no âmbito das seis instituições investigadas na segunda etapa da pesquisa qualitativa do Projeto GERES.

Gráfico 1: Desempenho médio em leitura das seis escolas municipais nas duas primeiras avaliações

do GERES (março e novembro de 2005)

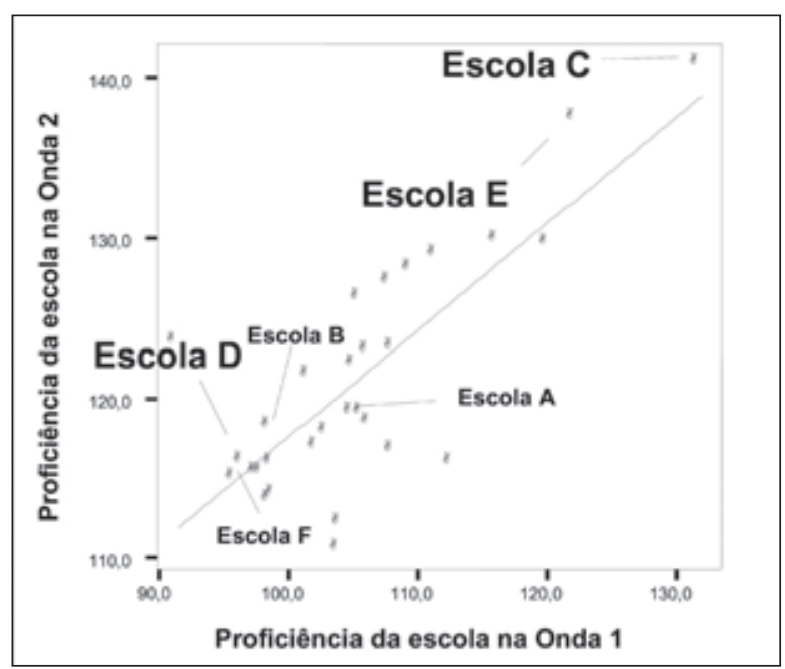

Fonte: GERES (2006).

Como ilustra o Gráfico 1, no patamar mais elevado encontra-se a Escola C, com as maiores proficiências em leitura ${ }^{3}$ nas avaliações de março e novembro do ano letivo de 2005 (131,94 e 140,96,

${ }^{3}$ É importante ressaltar que, em leitura, o intervalo total da escala de proficiência do projeto (Anexo II) vai de "menor que 50" a 200, sendo ela dividida em sete intervalos de 25 pontos. respectivamente); a Escola D, próxima ao patamar mais baixo da escala, apresenta uma das menores proficiências $(96,71$ e 116,1); a Escola E, próxima à Escola C, também apresenta proficiências elevadas (122,48 e 137,51). No caso dessas escolas, os dados indicam que, para além do inevitável erro de medida, existem variáveis internas a essas escolas e turmas que estão incidindo sobre o desempenho dos alunos. A partir desses resultados, a escolha das três escolas foi feita incluindo escolas cujas turmas apresentaram proficiência acima, em torno e abaixo da média geral, de modo que viabilizasse o contraste entre as escolas e as turmas dentro das escolas. Essas escolas pertencem à rede municipal de ensino, estão localizadas em bairros da Baixada Fluminense e da zona oeste do Rio de Janeiro e atendem um público constituído majoritariamente por alunos oriundos de classes populares.

A Escola $\mathrm{C}$, que atingiu as maiores proficiências no GERES no ano de 2005, possui uma turma participante do Projeto GERES composta por trinta e um alunos. Localizada no bairro de Senador Vasconcelos, próximo a Campo Grande, zona oeste da cidade do Rio de Janeiro, ocupa uma área pequena, no seio de uma comunidade próxima à linha do trem. A Escola $\mathrm{D}$, que apresentou as menores proficiências, funciona num Centro Integrado de Educação Pública (CIEP) e atende uma clientela composta por moradores das comunidades e favelas do seu entorno, Costa Barros, bairro próximo à Pavuna, na zona norte da cidade do Rio de Janeiro. Está próxima a várias comunidades carentes cujos comandos do tráfico são rivais, fato que expõe frequentemente a escola à violência urbana. Noventa e oito alunos estão distribuídos nas quatro turmas que participam do GERES na escola. A Escola E, que, ao lado da Escola C, conquistou as proficiências mais altas, fica dentro de um dos grandes condomínios de classe média alta do bairro Barra da Tijuca, na zona oeste. O condomínio é localizado numa das avenidas mais movimentadas do bairro e os alunos, embora oriundos de comunidades localizadas em áreas nem sempre muito próximas do condomínio, são transportados por ônibus, kombis e vans. Setenta e seis alunos participam do projeto nessa instituição. 
Foram realizadas três incursões (início, meado e final do ano letivo de 2007) aos estabelecimentos de ensino para coleta de registros fotográficos. Ao fim das incursões, obteve-se um acervo iconográfico composto por cerca de 1.500 fotografias, o que nos permitiu sistematizar os diferentes espaços escolares destinados ao desenvolvimento de habilidades de leitura.

Para a análise dos dados fotográficos, foram utilizadas as categorias cunhadas por Viñao Frago (2005): existência; especificidade; localização; acessibilidade; disposição e configuração interna dos objetos, mediante adaptação prévia para nosso objeto de estudo. Outras dimensões foram de fundamental importância para a análise dos murais presentes na escola: tipo de suportes de escrita e de materiais expostos; frequência da substituição; autoria; estado de conservação; existência de possíveis indícios de práticas pedagógicas voltadas para o ensino da língua. No caso das salas de leitura, levou-se em consideração também a quantidade e diversidade do acervo, bem como a presença de profissional responsável pelo desenvolvimento de atividades no local.

\section{Análise do corpus}

No que concerne aos espaços dos murais ou outros suportes de leitura com finalidade semelhante, percebe-se que, na instituição onde se atingiram as proficiências mais altas (Escola $\mathrm{C}$ ), a importância a eles atribuída fica expressa pelo cuidado, pela organização, pelo capricho e pelo zelo, tanto com os murais em si como com as produções dos alunos e demais materiais expostos. Os murais, igualmente distribuídos em todas as áreas externas do estabelecimento, são, de maneira geral, bem conservados e têm conexão com os projetos desenvolvidos na escola a cada período, indicando nitidamente a proposta de cada uma das atividades de forma integrada. Além disso, atendem às funções a que se propõem e trazem consigo uma concepção de leitura e de leitor que enfatiza o uso social da leitura, o acesso à diversidade textual, o investimento e o compromisso com a formação de leitores e produtores de textos.
$\mathrm{Na}$ Escola D predominam os varais e há, em menor quantidade, murais, mesas, grades móveis e fixas. Distribuídos de maneira desigual, os suportes concentravam-se, durante a pesquisa, no local de maior circulação de pessoas: o segundo pavimento da escola, nas proximidades da dependência administrativa. Nos demais ambientes da instituição havia pouco ou nenhum suporte de leitura, como foi o caso do corredor do terceiro pavimento e do pátio da escola, locais onde não existiam murais, embora os alunos circulassem intensamente por esses locais. A maior parte dos materiais expostos era composta por painéis confeccionados pelo corpo docente e tarefas escolares e imagens estilizadas coloridas pelos alunos, caracterizadas pela sua homogeneidade e pela recorrência nas formas de organização, na maior parte das vezes com trabalhos sobrepostos, o que dificultava a leitura dos materiais que ficavam por baixo. Nesse caso, não parecia haver critérios claros para a organização dos suportes, tampouco para a finalidade a que se propunham. Também não foi possível perceber a integração entre os assuntos trabalhados nos murais e varais. Fatos como o mau estado de conservação em que a maior parte dos materiais se apresentava, o deslocamento de cartazes e até de varais inteiros de um pavimento para outro ou de uma parede para outra no mesmo andar do prédio, a desatualização dos temas expostos e a manutenção de um mesmo mural ao longo de muitos meses constituem indícios de que a função principal dos suportes era decorar o interior do estabelecimento de ensino. E ainda a concentração de suportes de leitura na entrada do segundo pavimento, local de maior fluxo de pessoas na escola, pode indicar a priorização da "exposição" de tarefas escolares para o público, em detrimento da comunicação com os próprios estudantes e da colocação desses espaços a serviço da aprendizagem.

Quando se trata da quantidade e da finalidade dos espaços dos murais, podemos dizer que estes são aspectos que aproximam a Escola E da Escola C. Em ambas havia diversos murais instalados nos ambientes do estabelecimento, cada qual com uma finalidade distinta e em muitos casos evidente. Alguns 
murais localizados nas áreas da escola encontravamse integrados por temas comuns, como os dos Jogos Pan-Americanos. A presença de títulos nos suportes analisados e a relação destes com as produções dos alunos da Escola $\mathrm{E}$ forneceram indícios de que parte das atividades pedagógicas é desenvolvida com a finalidade de serem expostas nos espaços dos murais. A preocupação em expor diferentes gêneros discursivos, como cartazes informativos, receitas, textos narrativos longos e curtos, poesias e desenhos, é uma marca dos murais presentes no pátio da Escola E. Ademais, as imagens e os textos são utilizados de maneira equilibrada, e a organização dos materiais expostos permitia a leitura prática e agradável dos conteúdos.

Essas características tornam-se mais claras quando comparamos diferenças na abordagem pedagógica do mesmo tema nas três escolas; por exemplo, os Jogos Pan-Americanos.

Enquanto na Escola $\mathrm{C}$ o evento esportivo foi tema de produções textuais de alunos, de conselhos nutricionais e, além disso, de mensagens positivas que expunham a expectativa da instituição sobre os estudantes (Figuras 1 e 2) e na Escola E inspirou torneios esportivos disputados entre as turmas do estabelecimento, bem como a elaboração de uma poesia construída coletivamente pelas crianças acompanhada por produções artísticas (Figuras 3 e 4), na Escola D os Jogos Pan-Americanos serviram de temática de um painel que expunha desenhos estilizados produzidos por professores e alunos (Figura 5).

Figura 1: Escola C - Mural da escola

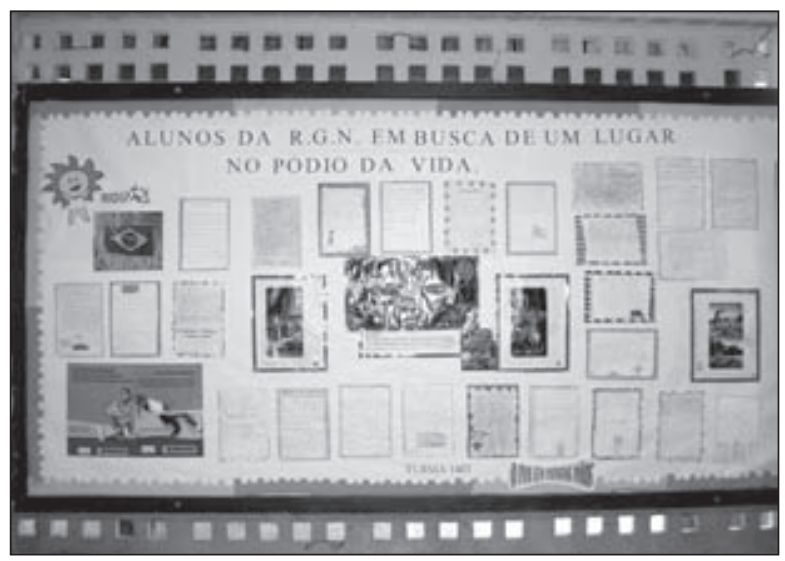

Figura 2: Escola C - Material exposto Mural da escola

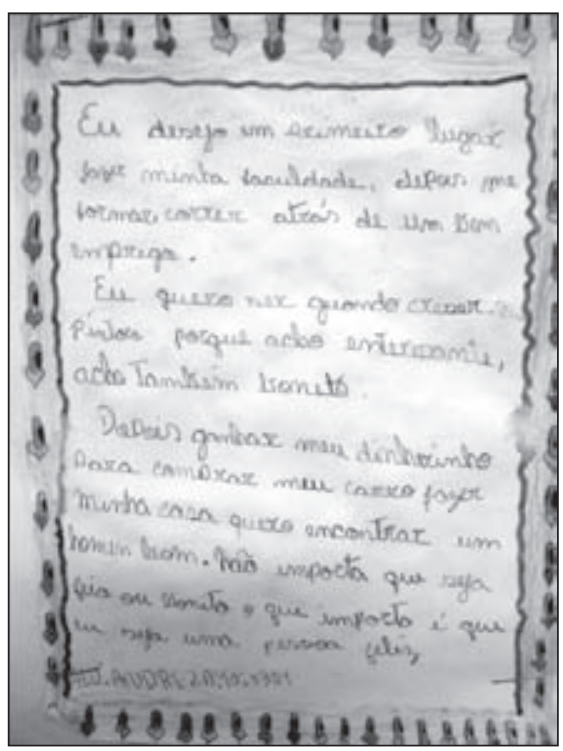

Figura 3: Escola D - Mural da escola

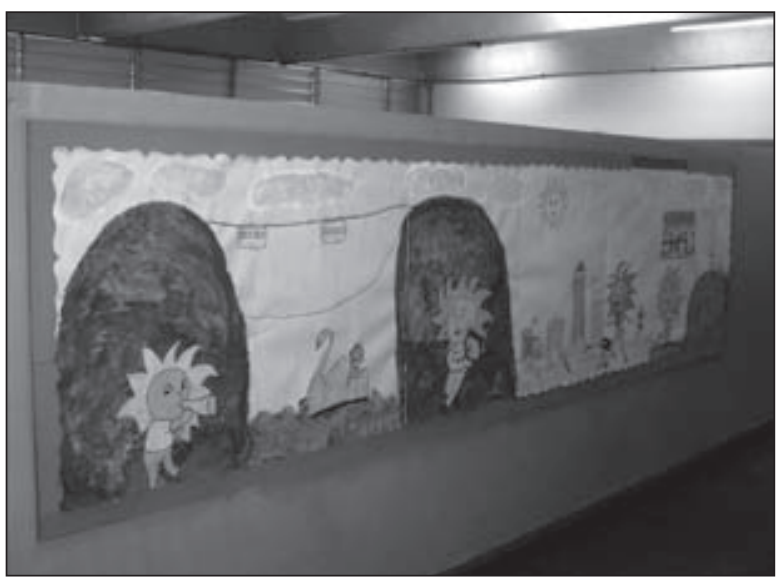

Figura 4: Escola E - Mural da escola

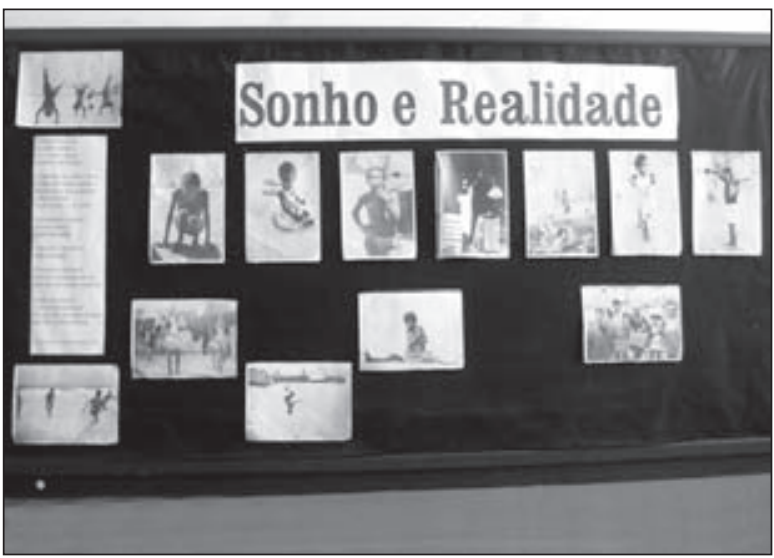


Figura 5: Escola E - Material exposto Mural da escola

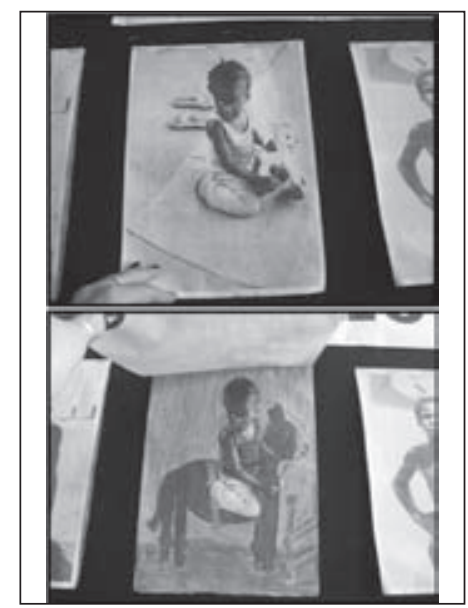

Em relação aos espaços dos murais das salas de aula, percebemos que, de maneira similar aos achados referentes aos murais das escolas, as turmas que atingiram desempenhos mais altos nos testes de leitura do GERES priorizavam a exposição de produções de alunos, ao invés de painéis e cartazes confeccionados por professores.

Nas turmas com maiores resultados escolares (turmas pertencentes às Escolas C e E), a prioridade é a exposição de materiais provenientes de atividades desafiadoras, como produções textuais de alunos (Figuras 6 e 8). Novamente alinhadas aos demais suportes de leitura presentes nos espaços das instituições de ensino, nas salas de aula das Escolas C e E observamos características como a atualização constante dos temas, a boa conservação dos suportes e materiais em exposição, a clareza da função e das propostas pedagógicas, além da sintonia com os projetos da escola como um todo. Esse conjunto de aspectos nos leva a verificar que, nas duas instituições, há uma tendência ao aproveitamento da utilização dos espaços dos murais para fins pedagógicos de incentivo a práticas leitura e escrita, que podem revelar um clima escolar cujo foco é a aprendizagem dos alunos.

Em contrapartida, nas turmas pertencentes à Escola D, que apresentaram as menores proficiências em leitura, a prioridade identificada foi a exposição de painéis confeccionados pelas professoras e decorados com imagens estilizadas de personagens infantis (Figura 7). Esses painéis, na maioria das salas de aula, permaneceram intactos ou sofreram alterações praticamente imperceptíveis ao longo do ano e pareciam ter como finalidade a decoração do ambiente. Além disso, os varais dessas salas de aula apresentavam características semelhantes àqueles localizados nos corredores do estabelecimento de ensino: mau estado de conservação decorrente da falta de atualização dos temas em exposição, pouca clareza das propostas pedagógicas dos materiais em exposição e predomínio de elementos visuais como desenhos prontos ou elaborados pelos professores.

Figura 6: Escola C - Mural da sala de aula Turma 1401

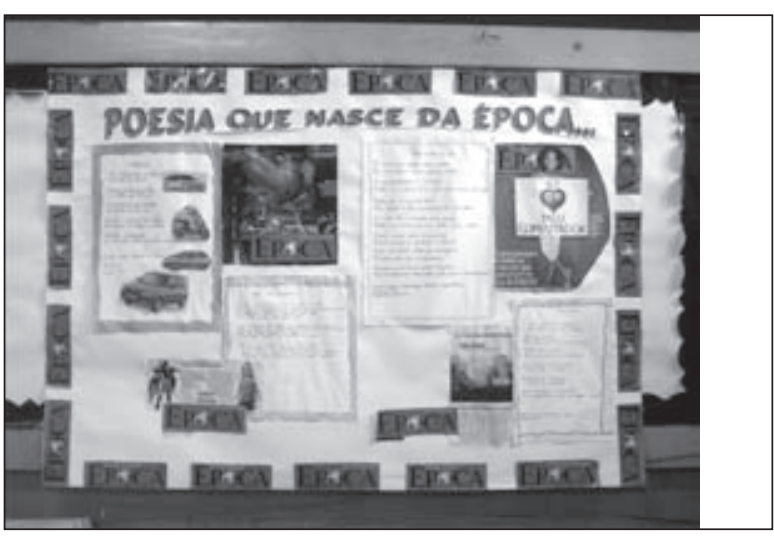

Figura 7: Escola D - Mural da sala de aula Turmas 1401, 1402, 1403 e 1404

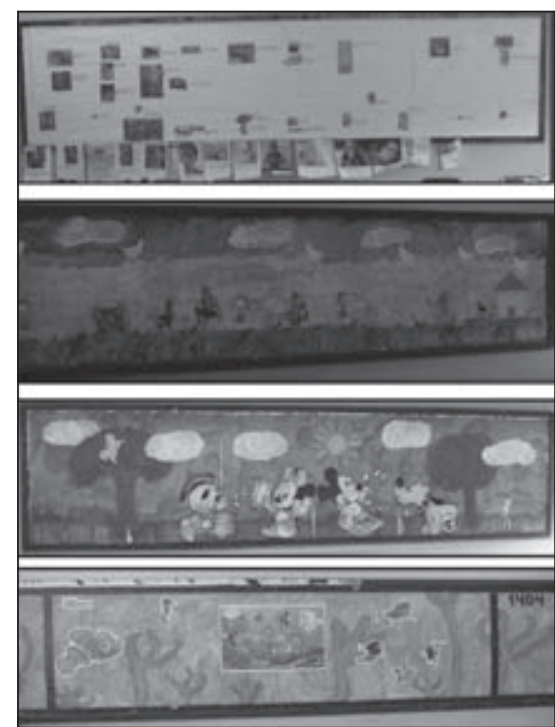


Figura 8: Escola E - Mural da sala de aula Turmas 1401, 1402/1403

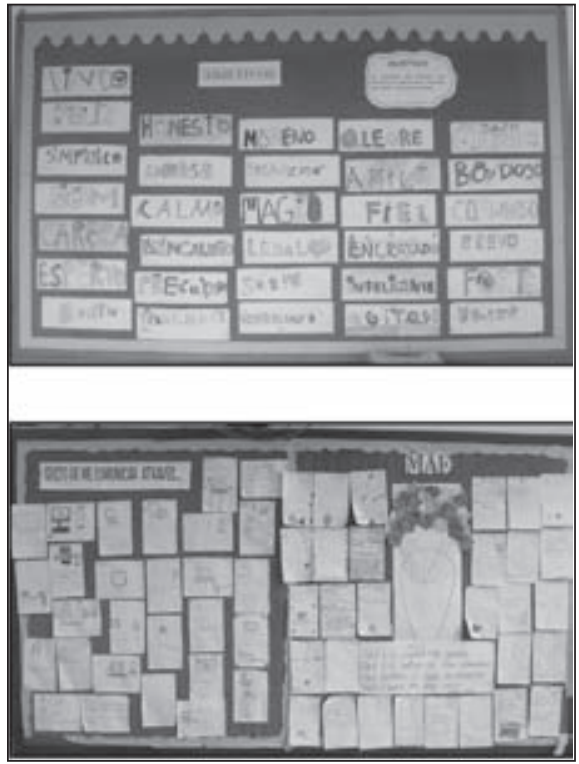

No que diz respeito aos materiais afixados nos murais e nos varais das salas de aula, verificou-se novamente que as turmas dos estabelecimentos de ensino que apresentaram as maiores médias de proficiência em leitura também guardam características peculiares em relação às salas de aula das demais turmas analisadas.

Figura 9: Escola C - Material exposto Mural da sala de aula - Turma 1401

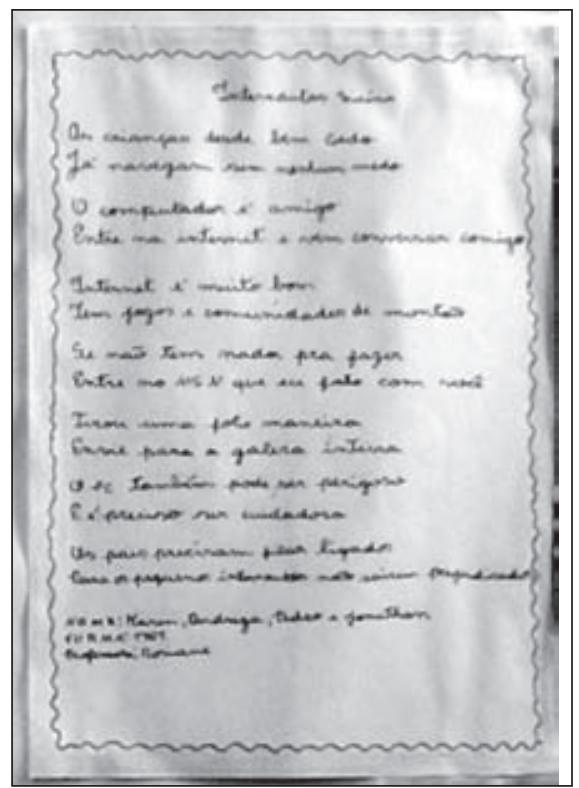

As turmas das Escolas C e E expunham majoritariamente textos de alunos cujo nível de elaboração é mais complexo em comparação às produções textuais encontradas nos varais das turmas da Escola D. Nas turmas das Escolas $\mathrm{C}$ e E foi possível identificar o desenvolvimento de práticas pedagógicas com ênfase no uso social da língua associado a seus aspectos formais e na formação do leitor/escritor com foco na produção textual e no acesso a diversos gêneros discursivos (Figuras 9 e 11). Nas turmas da Escola D, a pequena quantidade de produções textuais encontrada era constituída, em sua maioria, de cópias de materiais de pesquisa. A maior parte dos materiais tinha sido confeccionada pelas professoras e a ênfase era dada aos aspectos formais de uso da língua, assim como de apropriação do código alfabético (Figura 10).

Figura 10: Escola D - Material exposto - Mural da sala de aula - Turmas 1401, 1402, 1403 e 1404

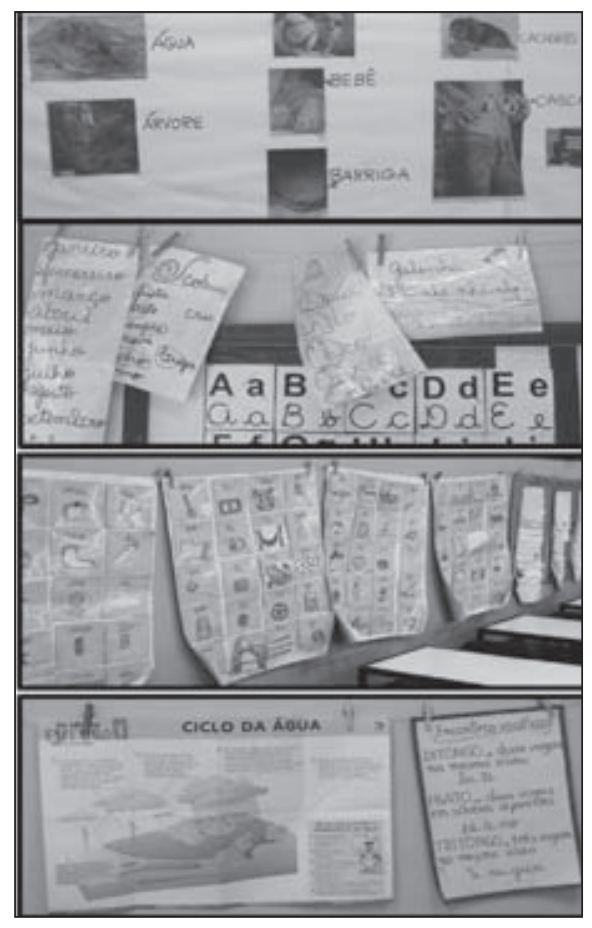

De maneira similar aos demais aspectos relacionados aos outros espaços escolares voltados para as práticas leitoras, percebemos que as salas de leitura das instituições onde os alunos atingiram os maiores desempenhos também possuem características singulares. 
Assim, no caso das Escolas C e E, existem espaços específicos para a sala de leitura acessíveis à comunidade escolar, nos quais são realizados empréstimos das obras; há um acervo diversificado e devidamente catalogado, organizado de forma adequada para atender ao público infantil; as salas dispõem de profissionais exclusivos para o desenvolvimento de atividades no espaço, além de serem dotadas de recursos audiovisuais. Estas salas são utilizadas unicamente para práticas relacionadas à leitura e à escrita (Figuras 12 e 14).

Figura 11: Escola E - Material exposto - Mural da sala de aula - Turmas 1401, 1402/1403

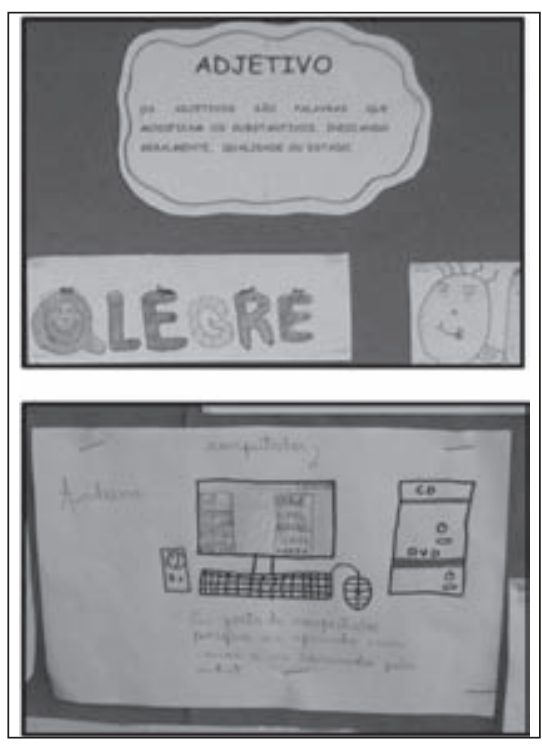

Figura 12: Escola C - Sala de leitura

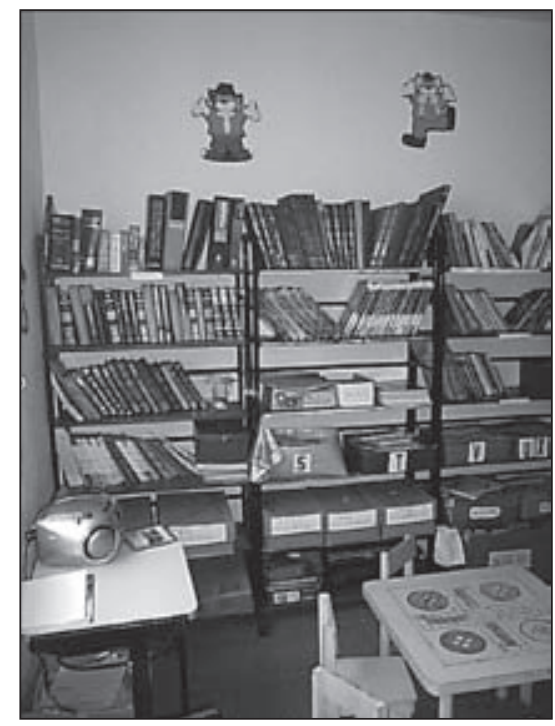

Na Escola D, embora houvesse um espaço amplo destinado à sala de leitura, o local permaneceu inacessível aos alunos e à comunidade escolar durante a pesquisa. Ao contrário das outras instituições analisadas, não havia nesta escola um profissional responsável pelo espaço, que era utilizado para armazenar diferentes objetos além dos livros do acervo. Muitas das obras bibliográficas não se encontravam catalogadas e não foi registrada a existência de recursos audiovisuais no local (Figura 13).

Figura 13: Escola D - Sala de leitura

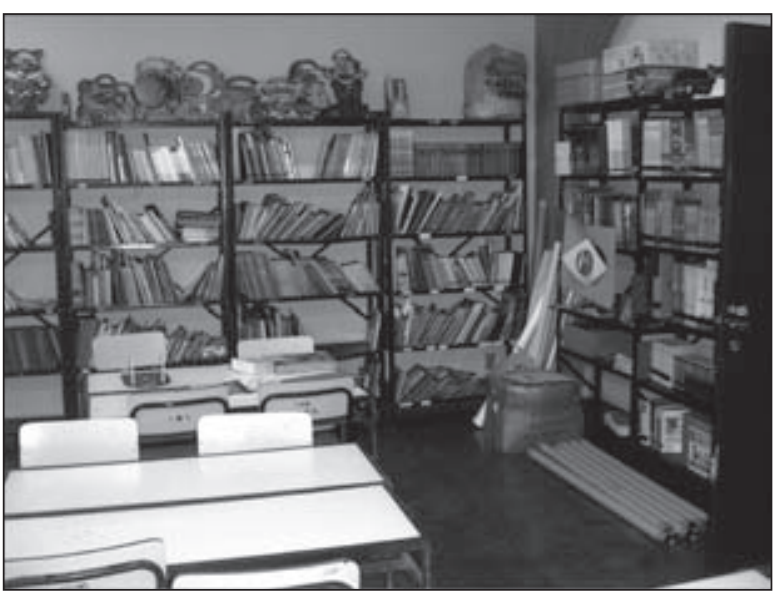

Figura 14: Escola E - Sala de leitura

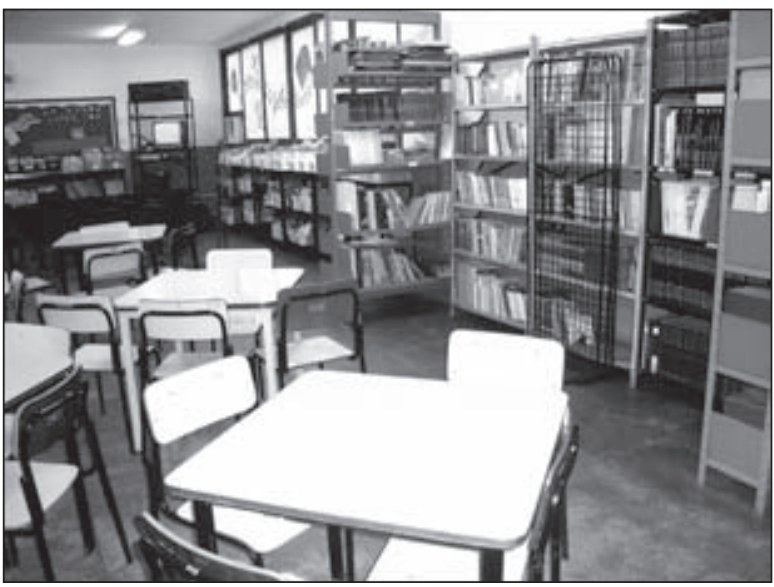

Quando analisamos os cantinhos de leitura presentes nas salas de aula, constatamos que eles seguiram a mesma tendência dos demais espaços destinados ao desenvolvimento de práticas leitoras analisados. Desta forma, foi recorrente a existência 
de pequenas bibliotecas no interior das salas de aula onde estudam os alunos que atingiram os maiores desempenhos em leitura. Na mesma direção, esses espaços, que comportavam um acervo diversificado de materiais de leitura, ficavam acessíveis aos alunos das turmas, que poderiam levar os livros para casa ou manuseá-los no próprio ambiente escolar ou da sala de aula (Figuras 15 e 17). No contexto da Escola $\mathrm{D}$, somente uma das turmas dispunha de um espaço reservado ao cantinho de leitura, que colocava à disposição um pequeno acervo composto por livros de literatura infantil (Figura 16).

Figura 15: Escola C - Cantinho de leitura Turma 1401

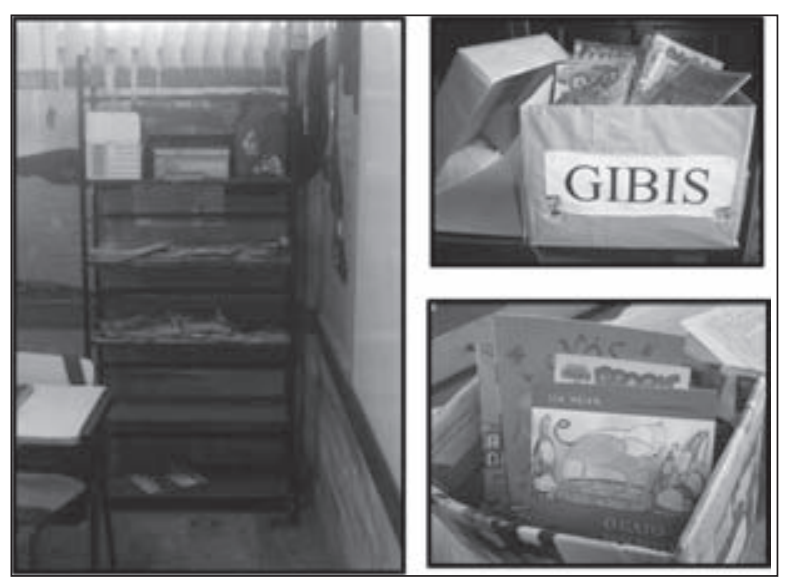

Figura 16: Escola E - Cantinho de leitura Turmas 1401, 1402/1403

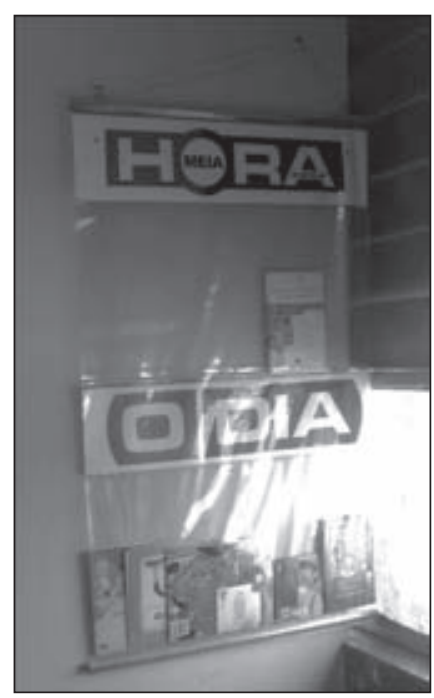

Figura 17: Escola D - Cantinho de leitura -

Turma 1402

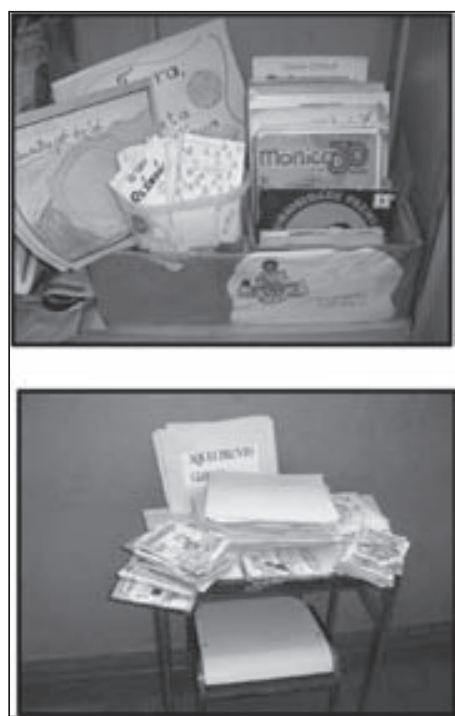

\section{Conclusões}

Os resultados desta pesquisa confirmam a teoria de que, por meio da investigação dos espaços da escola, é possível recolher indícios de diferentes práticas pedagógicas e culturas escolares e reafirma a ideia de que, na escola, há concepções de ensino-aprendizagem da leitura e da escrita subjacentes à definição dos espaços para atividades individuais e grupais, ao lugar destinado aos livros e outros suportes da escrita, à existência e uso de cantinhos de leitura nas salas de aula.

Foi possível identificar, além disso, que as instituições de ensino que atingiram maiores desempenhos (Escolas C e E) apresentam espaços com características diferenciadas em relação àquela com menores desempenhos (Escola D). Essas características estão relacionadas à importância, à natureza e às funções atribuídas aos espaços e recursos escolares. Os materiais expostos nos murais e varais também apresentaram muitas peculiaridades, em especial quando se tratava de indícios de práticas pedagógicas realizadas no interior das salas de aula e do enfoque dado à leitura. Por sua vez, essas características constituem oportunidades ou constrangimentos para o ensino de leitura e se revelam nos níveis de proficiência alcançados pelos alunos. 
No que compete aos espaços dos murais das escolas, percebemos, de maneira geral, que as instituições com desempenho mais alto nos testes de leitura do Projeto GERES priorizavam a exposição de produções de alunos ao invés de painéis confeccionados por professores. A ênfase das escolas com maiores resultados escolares (Escolas C e E) foi a exposição de materiais provenientes de atividades desafiadoras, como produções de texto relacionadas a imagens, enquanto na Escola $\mathrm{D}$ as atividades pareciam ter por objetivo decorar, com desenhos prontos e ilustrações mimeografadas. Outras características dos murais das Escolas C e E são a atualização constante dos temas, a boa conservação dos suportes e materiais em exposição, clareza da função a que se destinam no âmbito escolar e das propostas pedagógicas, além da sintonia com os projetos ali desenvolvidos. Com isso, pode-se constatar que as duas instituições aproveitam a utilização dos espaços dos murais para fins pedagógicos de incentivo a práticas leitura e escrita. Entretanto, a Escola D, que apresentou as menores proficiências em leitura entre as três instituições de ensino investigadas, além de priorizar a exposição de elementos visuais, muitas vezes de imagens estilizadas e confeccionadas pelo corpo docente, apresenta murais e varais com características como funções pouco definidas, mau estado de conservação decorrente da falta de atualização dos temas em exposição e falta de clareza das propostas pedagógicas dos materiais em exposição.

Com relação aos materiais presentes em murais e/ou varais, verificou-se que os estabelecimentos de ensino que apresentaram as maiores médias de proficiência em leitura também guardavam características peculiares em relação à outra instituição analisada. A Escola C, semelhante à Escola E, expunha, na maior parte dos murais, textos de alunos cujo nível de elaboração era mais complexo, em comparação às produções textuais encontradas nos varais da Escola D. Nas Escolas C e E, os materiais possuíam como característica a utilização de textos dissertativos e narrativos, bem como de outros gêneros discursivos (poesias, questionários e outros) adequados aos temas propostos, apresentação de ideias claras, coesas e encadeadas de maneira coerente, uso de vocabulário diversificado, escrita de letras legíveis e sem rasuras e com poucos problemas ortográficos, gramaticais ou de pontuação.

Em suma, embora não se possa afirmar que a presença, utilização e os diferentes arranjos dos espaços didático-pedagógicos analisados expliquem as proficiências médias das Escolas C, D e E, é possível dizer que as características identificadas nos registros fotográficos explicitam diferentes concepções de leitura, de práticas pedagógicas de ensino da língua e de aspectos materiais do clima acadêmico (ou ambiente escolar) sintonizadas, em maior ou menor medida, com a aprendizagem dos alunos.

Nessa perspectiva, as instituições com desempenho mais alto nos testes de leitura do Projeto GERES, as Escolas $\mathrm{C}$ e E, de maneira geral, pareceram dirigir seus esforços para organizar e disponibilizar seus espaços didático-pedagógicos especialmente voltados para as práticas leitoras, de maneira a otimizar os processos de ensino-aprendizagem dos alunos. Em contrapartida, a Escola D, que atingiu desempenhos inferiores aos das outras duas instituições analisadas, mesmo dispondo de recursos e espaços como murais, varais e sala de leitura, não os coloca a serviço da aprendizagem dos educandos, além de não contar com pequenas bibliotecas no interior de suas salas de aula.

Este estudo contribui para preencher uma lacuna existente no campo educacional no país, pois, conforme ressaltam Faria e Filho et al. (2004), Viñao Frago (2001, 2005) e Vidal (2005), são poucos os estudos sobre as instituições escolares que oferecem aos pesquisadores em educação subsídios para pensar a relação dos espaços e recursos materiais dos estabelecimentos de ensino com as práticas pedagógicas e a cultura escolar. O estudo realizado representa, ainda, uma abertura para novos diálogos na área da educação, seja com a pesquisa, seja com as políticas e práticas escolares, além de se constituir em ponto de partida para o desenvolvimento sistemático de novos estudos baseados nos espaços, objetos e recursos escolares, envolvendo desenhos diferenciados de pesquisa. 
Do ponto de vista das políticas e práticas pedagógicas, o quadro que a pesquisa desenha explicita que as modalidades de uso e as funções assumidas pelos espaços e recursos escolares no contexto de cada escola e de cada turma colocam oportunidades e constrangimentos para o desenvolvimento das habilidades de leitura e escrita relacionados aos esforços da instituição para transformar seus recursos em bons resultados escolares. Assim, em cada escola e em cada turma estudada as formas desse aproveitamento são diferentes, o que não apenas ilustra a variada gama de possibilidades de articulação de esforços pedagógicos e usos de recursos escolares como também sugere que o tipo de apoio que pode permitir avançar na promoção da aprendizagem e no desenvolvimento institucional da unidade escolar não responde a uma receita única, mas sim a estratégias diferenciadas que têm em comum o compromisso com os alunos.

\section{Referências bibliográficas}

ALBERNAZ, Ângela; FERREIRA, Francisco; FRANCO, Creso. A escola importa? Determinantes da eficiência e da equidade no ensino fundamental brasileiro. Pesquisa e Planejamento Econômico, Rio de Janeiro, v. 23, n. 3, p. 453-476, 2002.

BARBOSA, Maria Eugênia Ferrão; FERNANDES, Cristiano. A escola brasileira faz diferença? Uma investigação dos efeitos da escola na proficiência em Matemática dos alunos da $4^{\text {a }}$ série. In: FRANCO, C. Promoção, ciclos e avaliação educacional. Porto Alegre: Artmed, 2001. p. 155-172.

BERNADO, Elisangela; FELIPE, Luiza; PEDROSA, Fernanda. Fatores e resultados escolares no município do Rio de Janeiro: um estudo exploratório a partir dos dados do GERES 2005. In: ENCONTRO NACIONAL DE DIDÁTICA E PRÁTICA DE ENSINO, 14., Porto Alegre, 2008. Anais... Porto Alegre: s.ed., 2008. 1 CD-ROM.

CARVALHO, Marlene Alves de Oliveira. Alfabetizar e letrar: um diálogo entre a teoria e a prática. Petrópolis: Vozes, 2005.

FARIA FILHO, Luciano Mendes de; GONÇALVES, Irlen Antônio; VIDAL, Diana Gonçalves; PAULILO, André Luiz. A cultura escolar como categoria de análise e como campo de investigação na história da educação brasileira. Educação e Pesquisa, São Paulo, v. 30, p. 139-159, 2004.
FRANCO, Creso; BONAMINO, Alicia. A pesquisa sobre características de escolas eficazes no Brasil: breve revisão dos principais achados e alguns problemas em aberto. Revista Educação On-line, Rio de Janeiro: PUC-Rio, n. 1, 2005. Disponível em: <http://www. maxwell.lambda.ele.puc-rio.br>. Acesso em: 10 nov. 2007.

FRANCO, Creso; ORTIGAO, Isabel; ALBERNAZ, Ângela; BONAMINO, Alicia Catalano; AGUIAR, Glauco; ALVES, Fátima; SATYRO, Natália. Eficácia escolar en Brasil: investigando prácticas y políticas escolares moderadoras de desigualdades educacionales. In: CUETO, Santiago (Org.). Educación y brechas de equidad en América Latina. Santiago: Preal, 2006. p. 223-249. MORTATTI, Maria do Rosário Longo. História dos métodos de alfabetização no Brasil. In: . Alfabetização e letramento em debate. Brasília: Portal MEC, 2006. v. 1. Disponível em: <http:// www.smec.salvador.ba.gov.br/site/documentos/espaco-virtual/ espacoalfabetizar-letrar/lecto-escrita/artigos/historia\%20dos\%20 metodos.pdf>. Acesso em: 5 maio 2007.

PEDROSA, Fernanda. Clima acadêmico e a promoção da aprendizagem nos anos iniciais do ensino fundamental. Dissertação (Mestrado em Educação) - Pontifícia Universidade Católica do Rio de Janeiro, Rio de Janeiro, 2007.

SOARES, José Francisco. O efeito da escola no desempenho cognitivo de seus alunos. In: MELLO E SOUZA, Alberto (Org.). Dimensões da avaliação educacional. Petrópolis: Vozes, 2005. p. 174-204.

. Melhoria do desempenho cognitivo dos alunos no ensino fundamental. Cadernos de Pesquisa, São Paulo: Fundação Carlos Chagas, v. 37, n. 130, 2007. p. 135-160.

SOARES, Magda. Letramento e alfabetização: as muitas facetas. Revista Brasileira de Educação, Rio de Janeiro: Autores Associados, n. 25, 2003. Disponível em: <http://www.scielo.br/pdf/rbedu/ n25/n25a01.pdf $>$. Acesso em: 13 maio 2007.

VIDAL, Diana Gonçalves. Culturas escolares - estudo sobre práticas de leitura e escrita na escola pública primária (Brasil e França, final do século XIX). Campinas: Autores Associados, 2005. VIÑAO FRAGO, Antonio. Espaços, usos e funções: a localização e disposição física da direção escolar na escola graduada. In: BENCOSTA, Marcus L. A. (Org.). História da educação, arquitetura e espaço escolar. São Paulo: Cortez, 2005. p. 15-47.

.; ESCOLANO, Augustín. Currículo, espaço e subjetividade: a arquitetura como programa. Rio de Janeiro: DP\&A, 2001.

ROBERTAARAÚJO TEIXEIRA, mestre pela Pontifícia Universidade Católica do Rio de Janeiro (PUC-Rio), é doutoranda do 
Espaços, recursos escolares e habilidades de leitura de estudantes da rede pública municipal do Rio de Janeiro

Programa de Pós-Graduação em Educação da mesma instituição de ensino, membro do Laboratório de Avaliação da Educação (LAED) e bolsista da Coordenação de Aperfeiçoamento de Pessoal de Nível Superior (CAPES). Publicações recentes: Refletindo sobre as potencialidades do uso de espaços e recursos para o desenvolvimento de habilidades de leitura na escola (Boletim GERES, Belo Horizonte, n. 4, 2008); Objetos e espaços escolares como indicadores de culturas escolares promotoras de aprendizagem de habilidades de leitura: um estudo em três escolas públicas do município do Rio de Janeiro (In: SIMPÓSIO ESPAÇO EDUCAÇÃO, 1., Juiz de Fora, 2007. Anais... Juiz de Fora: s.ed., 2007); em coautoria com BONAMINO, Alicia M. C.; PEDROSA, Fernanda F.; OLIVEIRA, Lúcia G.; RODRIGUES, José R. S. Clima didático e interações em sala de aula (In: SEMINÁRIO GERES, Belo Horizonte: s.ed., 2008); em coautoria com PEDROSA, Fernanda. Um olhar sobre a escola: clima acadêmico e espaços privilegiados de leitura em estabelecimentos de ensino da rede pública do rio de janeiro (In: COLÓQUIO LUSO-BRASILEIRO SOBRE QUESTÕES CURRICULARES, 4., Florianópolis, 2008. Anais... Florianópolis: s.ed., 2008). Pesquisas em andamento: "Projeto Estudo da Geração Escolar 2005 - GERES" e "Cidade e escola: os efeitos da segregação residencial nas chances escolares de crianças e jovens”. E-mail: robertaateixeira@gmail.com

Recebido em outubro de 2008

Aprovado em fevereiro de 2009 
semiestructuradas. El referencial teórico está apoyado en autores vinculados a la historia de la cultura escrita y al campo de las prácticas de letrar. Algunas de las conclusiones de ese trabajo indican que la escrita de los diarios es, para el agricultor, "una forma de existir en el cotidiano”, de registrar su historia y la de su familia, de dejar huellas del pasado como una "herencia" a las nuevas generaciones. Entendemos que ese estudio trae contribuciones al campo de la cultura escrita en la medida que presenta la escrita como una compleja y significativa práctica social y cultural. En ese sentido, tratamos a los diarios como un patrimonio de lo escrito.

Palabras claves: cultura escrita; letrar; agricultor; diários.

Roberta Araújo Teixeira

\section{Espaços, recursos escolares e} habilidades de leitura de estudantes da rede pública municipal do Rio de Janeiro: estudo exploratório O artigo traz os resultados de um estudo exploratório realizado no ano de 2007 em três escolas municipais do Rio de Janeiro participantes do Projeto GERES (Estudo da Geração Escolar 2005). Considerando que os espaços escolares possuem importante dimensão educativa e que a materialidade da escola é fator relevante na constituição de práticas escolares capazes de constranger ou de estimular conhecimentos e competências, buscou-se compreender, no interior das escolas investigadas, o conjunto de fazeres pedagógicos ativados que guardam relação mais direta com o desenvolvimento de habilidades básicas de leitura e escrita. Foram utilizados registros fotográficos de salas de aula, cantinhos de leitura, murais e salas de leitura como fonte de dados. Identificaram-se aspectos relevantes das instituições pesquisadas pautados na natureza, disposição, usos e funções de espaços e objetos relacionados à promoção da leitura, contribuindo para o entendimento da eficácia escolar do ponto de vista dos discursos visuais da escola como fatores promotores de aprendizagem.

Palavras-chave: espaços escolares; eficácia escolar; habilidades de leitura.

Spaces, school resources and reading skills of students from the Rio de Janeiro municipal school system: an exploratory study

This paper presents the findings of an exploratory study conducted in 2007 in three municipal schools in Rio de Janeiro, Brazil, all participants in the 2005 School Generation Study (GERES) Project. As school spaces possess an important educational dimension and material aspects of school play a leading role in establishing educational practices that can curb or spur the dissemination of knowledge and skills, the set of teaching tasks examined in these schools focused mainly on the development of basic reading and writing skills. Data sources included photographs of classrooms, book nooks, bulletin boards and reading rooms, with significant aspects of these institutions identified by the types, layouts, uses and functions of spaces and objects designed to encourage reading. This analysis helps build up a better understanding of school effectiveness from the standpoint of the visual discourses presented by schools as factors underpinning the learning process.

Key words: school spaces; school effectiveness; reading skills.

Espacios, recursos escolares y habilidades de lectura de estudiantes de la red pública municipal de Rio de Janeiro: estudio exploratorio El artículo trae los resultados de un estudio exploratorio realizado en el año de 2007 en tres escuelas municipales de Rio de Janeiro participando del Proyecto GERES (Estudio de la Generación Escolar 2005). Considerando que los espacios escolares poseen importante dimensión en la educación y que la materialidad de la escuela es factor relevante en la constitución de prácticas escolares capaces de constreñir o de estimular conocimientos y competencias, se buscó comprender, en el interior de las escuelas investigadas, el conjunto de trabajos pedagógicos activados que guardan relación más directa con el desarrollo de habilidades básicas de lectura y escrita. Fueron utilizados registros fotográficos de salas de clase, rincones de lectura, murales y salas de lectura como fuente de datos. Se identificaron aspectos relevantes de las instituciones pesquisadas pautados en la naturaleza, disposición, usos $y$ funciones de espacios e objetos relacionados a la promoción de la lectura, contribuyendo para el entendimiento de la eficacia escolar bajo el punto de vista de los discursos visuales de la escuela como factores promotores de aprendizaje.

Palabras claves: espacios escolares; eficacia escolar; habilidades de lectura.

Maria Clara Di Pierro e

Marcia Regina Andrade

Escolarização em assentamentos no estado de São Paulo: uma análise da Pesquisa Nacional de Educação na

\section{Reforma Agrária 2004}

O estudo sobre a escolarização nos assentamentos rurais do estado de São Paulo, com base nos dados da Pesquisa Nacional de Educação na Reforma Agrária 2004, constatou que o direito à educação só estava assegurado às crianças que frequentavam as séries iniciais do ensino fundamental; nos demais níveis e modalidades, inclusive a educação de jovens e adultos, a oferta 